\section{BOOK REVIEW}

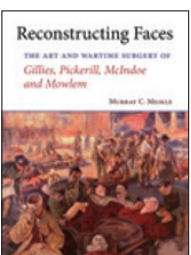

\section{RECONSTRUCTING \\ FACES: THE ART \\ AND WARTIME \\ SURGERY OF GILLIES, PICKERILL, MCINDOE AND MOWLEM}

M. C. Meikle, Otago University Press price €30.00; pp 264, ISBN 9781877578397

This book is written by Professor Meikle, emeritus professor in orthodontics at King's College London. It is an up-to-date retelling of the lives and work of the 'big four' plastic surgeons working in the United Kingdom during the First and Second World Wars. It outlines the journeys of these four influential surgeons, who all incredibly had roots in a small corner of New Zealand, and includes fascinating stories of their motivations and development.

The work is split into 12 intelligible chapters treading the line between the details of their medical and surgical work, and the recounting of theirs lives away from the operating table. There is also a chapter dedicated to the renowned 'Guinea Pig Club', as well as an appendix listing the entire club. Extensive appendices also include important staff and officers.

The text is well laid out and easy to enjoy whilst still being well researched and detailed from the start. The book is generously filled with figures and illustrations on virtually every page. Ranging from hand written notes to photographs to pastille drawings, the figures help to maintain the readers' interest throughout.

In addition a supplementary DVD includes live surgery footage performed by Rainsford Mowlem converted from original $16 \mathrm{~mm}$ footage, which stands as a testament to his skill and makes for fascinating viewing.

Whilst not aiming to be a guide to surgical techniques, as many may now be outmoded, it provides an enjoyable and informative backdrop to modern techniques in many instances. Although this is not a book on how to 'reconstruct faces', I can't imagine many plastic and maxillofacial surgeons who would not find this an enthralling read.

This beautifully presented hardback book is a rare thing in that it is of significant interest to both medical and dental practitioners as well as medical historians and would not be out of place even in a coffee table collection. The book suggests it is 'a must for anyone interested in the history of medicine' and I'm inclined to agree.

R. JOSHI

\title{
DENTAL TEAMS ENCOURAGED TO SUPPORT NO SMOKING DAY
}

This year's No Smoking Day will take place on 11 March 2015.

A new survey of 2,000 smokers by the British Heart Foundation (BHF) has found that less than one in two (44\%) smokers in the UK are worried about the negative effects of smoking on their teeth, and only one in four (27\%) are concerned about the effects of smoking on their gums.

With smokers risking damaging their oral health due to their habit, the BHF is encouraging dental professionals to use this year's No Smoking Day as an opportunity to raise awareness and boost participation among patients by promoting quit aids in their practice and local support services available in their area.

Dr Mike Knapton, BHF Associate

Medical Director, said: 'Dentists have always played a big role in raising awareness of No Smoking Day and the dangers of smoking. Dental clinics should consider promoting the event in their offices in the weeks leading up to No Smoking Day.

'Engaging your patients on the subject might help them take the first step towards a smoke-free life. Dental practices and dentists who want to get involved can visit NoSmokingDay.org. uk to order their organiser pack.'

Smokers are 7-10 times more likely to suffer from oral cancer than individuals who have never smoked. ${ }^{1}$

The BHF is calling on all smokers to attempt to quit on this year's No Smoking Day 2015. The theme is 'Proud to be a Quitter', which showcases the inspirational stories of ex-smokers.

To order or download the free No Smoking Day organiser pack, which includes posters, leaflets and a handbook, visit www.nosmokingday.org.uk.

1. Warnakulasuriya S, Sutherland G, Scully C. Tobacco, oral cancer, and treatment of dependence. Oral Oncol 2005; 41: 244-260. 